\title{
Analysis of changes in the coordinates of the "Tavaksay" geodynamic polygon
}

\author{
Erkin Mirmakhmudov ${ }^{1 *}$, Vahidjon Niyazov $^{2}$, Vazira Makhamatova ${ }^{1}$, Nozima Muminova ${ }^{1}$
}

\author{
${ }^{1}$ NUU, National University of Uzbekistan, 100104 Tashkent, Uzbekistan \\ ${ }^{2}$ SamSACEI, Samarkand State Architectural and Civil Engineering Institute, 140147 Samarkand, \\ Uzbekistan
}

\begin{abstract}
This article presents the results of GNSS and laser measurements at the "Tavaksay" geodynamic polygon. Describes the classical methods for determining the change in coordinates based on triangulation and leveling. Ways to improve the accuracy of local microplate tectonics using navigation systems are outlined here.The coordinates of the benchmarks were calculated in the rectangular GaussKruger coordinate system and the spatial system B, L, H for CK42 and WGS84.The trilateration method for determining the distances between points of the geodynamic network is analyzed. An assessment of the accuracy of the coordinates of points and the distances between them, depending on the number of measurement cycles, has been made.The accuracy of the trilateration and GNSS method for this network is graphically presented. The diagonal elements of the covariance matrix of GNSS measurements are investigated. It is proposed to make homogeneous GNSS and laser measurements at the tops of the hills at a certain time interval to study local deformation processes.
\end{abstract}

\section{Introduction}

The use of modern information and digital technologies in geodesy has led to the determination of the values of tidal deformations and the movement of masses in the upper layers of the earth's crust [1]. Such processes directly change the coordinate basis of the geodetic network, which must be taken into account when calculating coordinates. Considering the still unpredictable earthquakes, which affect the accuracy of determining the coordinates of points of the geodetic network, the task becomes more complicated. These minor changes (1-3 cm per year) can only be detected using special satellite systems. Therefore, the need to improve the accuracy of coordinates and determine geodetic constants is associated with new GNSS and satellite methods [2]. Reliable results can be obtained on special polygons located in various tectonic plates and seismic zones (Fig.1). Geophysical, chemical, geodetic, gravity and GNSS measurements should be taken at these polygons.

\footnotetext{
${ }^{*}$ Corresponding author: erkin_mir@mail.ru
} 


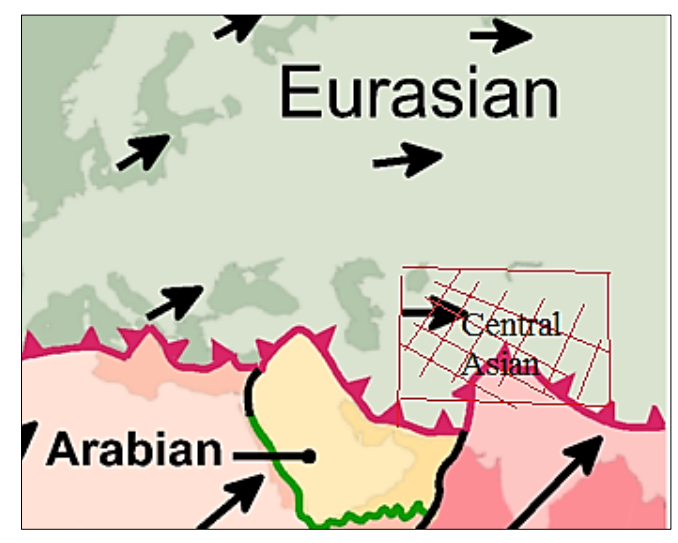

Fig.1. The territories of Central Asia

The progress of modern technology such as laser ranging of satellites, Doppler observations of satellites has led to an increase in the accuracy of determining rectangular coordinates and heights. Now it is possible to interpret not only the geoid model, but also to determine minor tectonic changes. Classical methods provide a fundamental basis for studying the Earth's gravitational field, but their disadvantage is the impossibility of performing continuous geodetic measurements. As a result, it is necessary to use the average value of measurements over a long observation period. Monitoring of deformations of individual areas is due to an increase in seismicity, as well as the influence of humans on the terrain.

These phenomena can be investigated using electronic geodetic instruments, but this will take a significant period of time. The introduction of modern satellite technologies reduces the time interval and increases the accuracy by 2-3 orders. In recent years, electronic and laser scanners have become widely used to determine the sides of geodetic networks.

\section{Problems}

Since part of the territory of Central Asia is located at the junction of three global and two local plates, the problem arises of determining the magnitude of the movements of these areas on the basis of GNSS receivers and precision geodetic instruments. Considering that Uzbekistan is located in a seismically active zone, the role of ground-based and satellite data acquires a special status (Fig.2). 


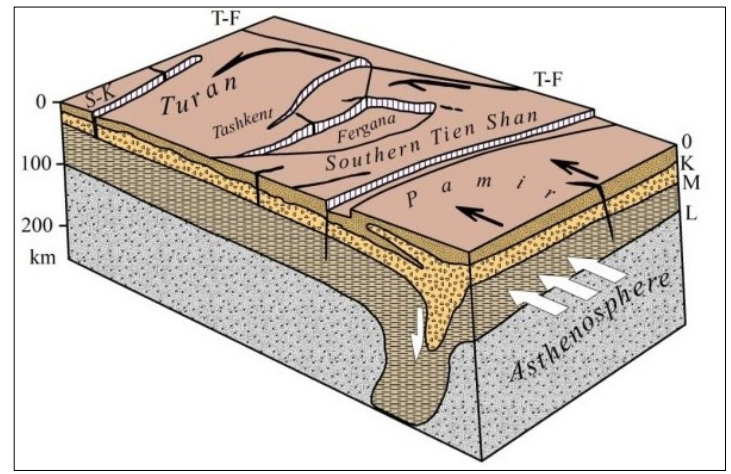

Fig.2. Scheme of tectonic faults in CA

After the Tashkent (1966) and Gazli (1976) earthquakes, geodynamic polygons were organized, where seismic and topographic measurements are performed. The Tashkent geodynamic polygon is located near industrial cities, covers the Charvak reservoir and other hydraulic structures, and is designed to ensure the safety of the operation of facilities [3]. From 1966 to 1998, triangulation and leveling were carried out in order to study earthquakes. According to the results of investigation in the northeastern suburb of Tashkent, a block subsidence of up to $2.3 \mathrm{~mm} /$ year (1992-1993) and a rise of up to $1.3 \mathrm{~mm} /$ year (2000-2002) were established.

In 2009-2010, specialists from the National Center for Geodesy and Cartography (NCGC) of Uzbekistan performed 4 cycles of GPS measurements at the SGN. Multiple repeated leveling of I and II order at the Tashkent geodynamic polygon led to the fact that there is a correlation between changes in the rates of vertical movements and deformations of the earth's crust (Fig. 3). Due to the lack of a systematic program of works, the results of processing traditional and satellite data remained incomplete. The problem is that geodetic, seismic, geophysical and GNSS measurements in Uzbekistan are carried out by specialized organizations that belong to different supervising departments and ministries.

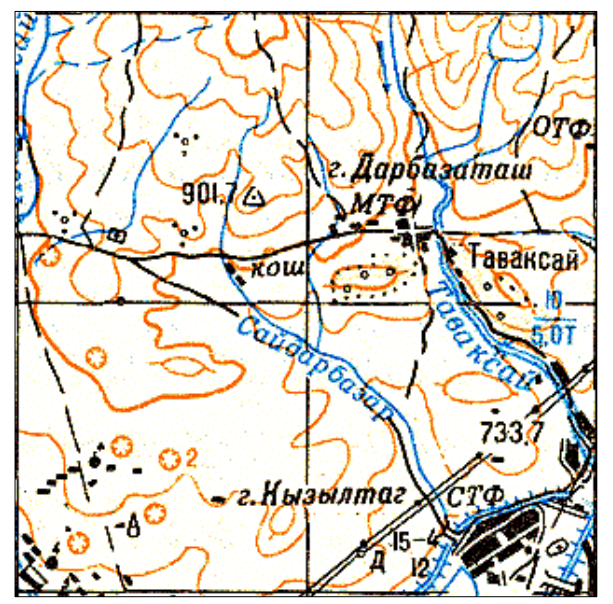

Fig.3. Fragment of a polygon map 


\section{Measurements}

Usually, according to geophysical and geological studies, zones are found that are most sensitive to deformations and tectonic actions. A geodesic quadrangle is designed in the form of a rhombus or parallelogram [4]. Moreover, the two sides of this figure should be located on different blocks or vertices, approximately parallel to the direction of the fault. For example, for the "Tavaksay" polygon, several quadrangles can be used, the points of which are located on the tops of the hills, and the "Karzhatay" fault passes under them (Fig. 4). The marks of triangulation and leveling in the vicinity of this polygon were installed by the geodetic enterprise, which later began to be used by the Institute of Seismology of the Academy of Sciences of the Republic of Uzbekistan for geodynamics.

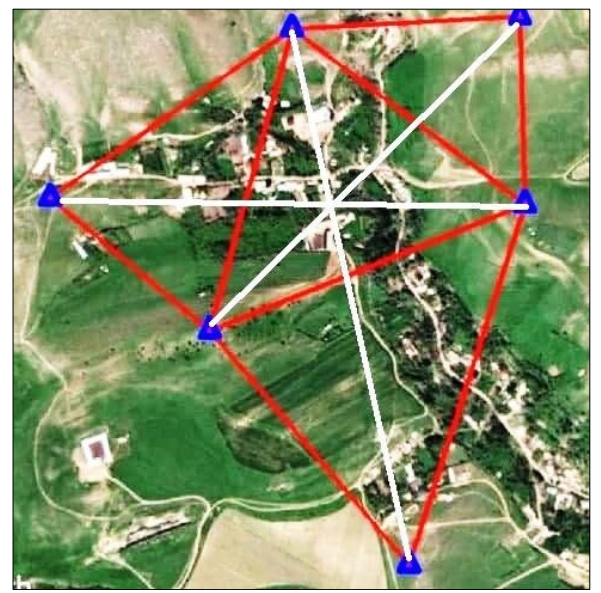

Fig.4. Scheme of a geodesic quadrangle

In 2021, employees of the department of geodesy and geoinformatics of the national university of Uzbekistan carried out geodetic workwith the GNSS R4 receiver and Trimble M3 total stations. During the reconnaissance, it was found that one point of this geodetic network (CIRC) is the benchmark of the Central Asian Geodynamic Network [5]. This station was used as a base station because in 1992-1996, spatial and geodetic coordinates were obtained, which are reduced to the ITRF96 system. The observation interval between sessions was set to 3 minutes for a 1.5 hour measurement cycle, since the influence of external factors was minimal. As a result, the coordinates of the points were obtained in the SK42 and WGS84 systems, as well as projections of distances in the directions N, E, Z and their root-mean-square errors. For each side, the elements of the covariance matrix are calculated, where the diagonal elements represent the parameters of the coordinate errors. The main PDOP ranged from 1.1 to 1.6, which indicates a good satellite configuration and due to the absence of ground obstacles. As for external factors, there is a certain systematic error associated with local climatic conditions [6].

\section{Calculations}

Based on the results of navigation and laser measurements, the coordinates of the points were obtained in the rectangular Gauss-Kruger coordinate system and the spatial spherical system $B, L, H$. The heights of each point are calculated relative to the reference ellipsoid 
and mean sea level MSL [7]. For the CIRC base station, latitude, longitude, altitude and Gauss-Kruger coordinates were calculated (Table 1).

Table1. Initial coordinates of the base station

\begin{tabular}{|c|c|c|}
\hline CIRC & WGS84 & CK42 \\
\hline $\mathrm{B}$ & $41^{\circ} 34^{\prime} 20.766^{\prime \prime}$ & $41^{\circ} 34^{\prime} 20.047^{\prime \prime}$ \\
\hline $\mathrm{L}$ & $69^{\circ} 39^{\prime} 39.090^{\prime \prime}$ & $69^{\circ} 39^{\prime} 41.770^{\prime \prime}$ \\
\hline $\mathrm{H}$ & $770.589 \mathrm{~m}$ & $805.911 \mathrm{~m}$ \\
\hline $\mathrm{X}$ & 4604440.020 & 4604418.212 \\
\hline $\mathrm{Y}$ & 12555118.680 & 12555180.944 \\
\hline
\end{tabular}

Since the PDOP accuracy indicator was within 1.2-1.6, the values of the coordinates of each point were stable throughout the entire measurement cycle. The criterion for assessing the accuracy is the RMS of the unit of weight, calculated from the measurement results, and the values of the diagonal elements of the covariance matrix (Table 2).

Table 2. Diagonal elements of the covariance matrix

\begin{tabular}{|l|l|l|l|}
\hline № & $\boldsymbol{\sigma}_{\mathbf{x}(\mathbf{m})}$ & $\boldsymbol{\sigma}_{\mathbf{y}(\mathbf{m})}$ & $\boldsymbol{\sigma}_{\mathbf{z}(\mathbf{m})}$ \\
\hline 1 & 0.002 & 0.003 & 0.003 \\
\hline 2 & 0.002 & 0.003 & 0.003 \\
\hline 3 & 0.002 & 0.004 & 0.004 \\
\hline 4 & 0.002 & 0.003 & 0.003 \\
\hline
\end{tabular}

Table 2 shows that the internal accuracy fluctuates at the level of 2-3 mm, which is considered a reliable criterion for studying tectonic displacements in a short time interval. However, the global coordinate accuracy differs from the internal accuracy by an insignificant amount and can be used as the main criterion for evaluating the results of calculations (Fig. 5). 


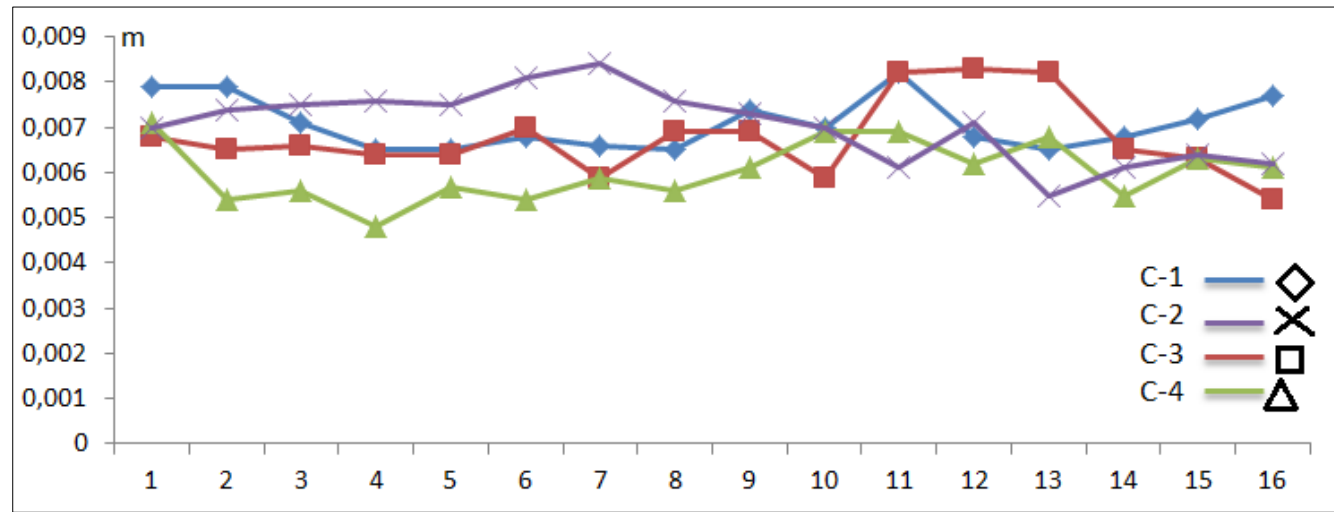

Fig.5. Dependence of the accuracy on the number of cycles

Figure 5 shows that the accuracy varies from 0.005 to $0.009 \mathrm{~m}$, which is sufficient for studying deformation processes and displacement of coordinates at the boundaries of faults. As already noted, the trilateration method for determining the distances between points will provide additional information for studying the drift of local plates. In the course of processing, scalar values of the radius of the vector between the points of the geodesic quadrangle in the direction of latitude, longitude and altitude were also calculated with RMS errors not exceeding $0.005 \mathrm{~m}$.

The GNSS calculation report shows the distance between the base station and the designated points. Data processing has led to the fact that the accuracy of the ellipsoidal distance, obtained on the basis of navigation measurements, does not exceed $0.001 \mathrm{~m}$. For comparison, the results of calculating the distances $\left(\mathrm{R}_{\mathrm{tr}}, \mathrm{R}_{\mathrm{gnss}}\right)$ using a tacheometer are shown (Fig.6).

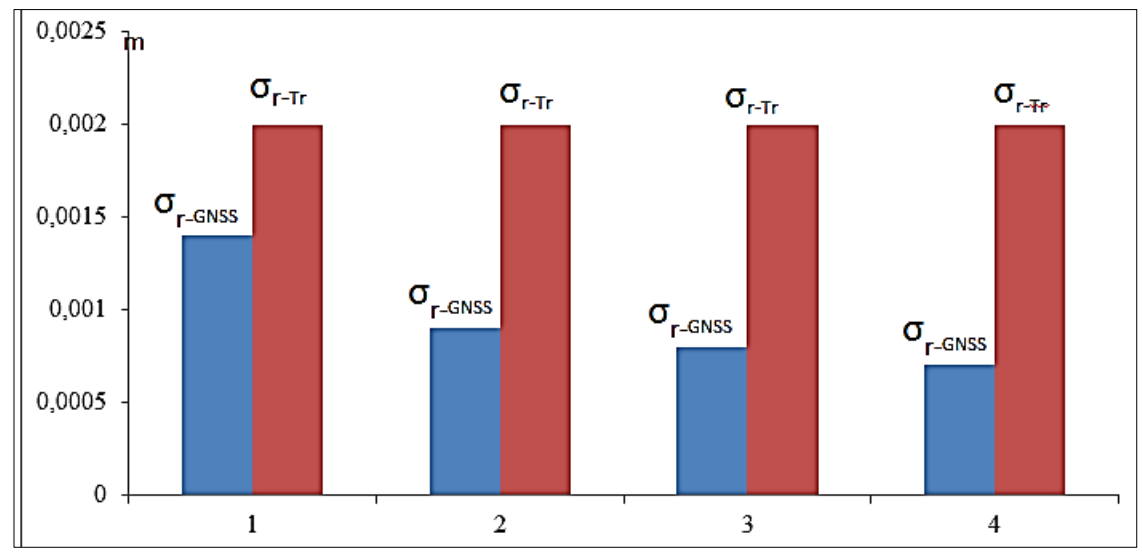

Fig.6. Accuracy of distance

Figure 6 shows that the accuracy obtained using GNSS is an order of magnitude higher than the accuracy of laser measurements. The difference between navigational and tacheometric data is due not only to instrumental RMS, but also to the calculation technique. As a result of processing navigation measurements, rectangular and spherical 
coordinates of points of the geodynamic network were obtained, which represent an array of data of geodynamic processes [8]. A preliminary analysis of the accuracy of measurements and calculations showed that observation errors correspond to the normal Gaussian distribution. This important criterion is the basis for further research on the adjustment of geodetic networks and the development of a coordinate change model $[9,10]$. Table 3 below shows the calculated rectangular and spherical coordinates based on the GNSS data.

Table 3. Coordinates of points of the geodesic quadrangle

\begin{tabular}{|c|c|c|c|c|c|}
\hline & $\mathrm{X}(\mathrm{m})$ & $\mathrm{Y}(\mathrm{m})$ & $\mathrm{B}_{\mathrm{wgs} 84}$ & $\mathrm{~L}_{\mathrm{wgs} 84}$ & $\mathrm{H}_{\mathrm{wgs} 84}$ \\
\hline $\mathrm{C}$ & 4604418.212 & 555180.944 & $41^{\circ} 34^{\prime} 20.766$ & 69³9'39.090" & 770.589 \\
\hline 4 & 4604511.723 & 554213.899 & 413424.034 & $69 \begin{array}{lll}69 & 38 & 57.381 \\
\end{array}$ & 774.531 \\
\hline 2 & 4604900.210 & 555222.062 & 413434.861 & 693918.159 & 797.660 \\
\hline 3 & 4604849.600 & 554692.462 & 413413.776 & 693910.550 & 777.006 \\
\hline ast & 4604197.524 & 554521.354 & 413436.361 & 693941.039 & 824.845 \\
\hline
\end{tabular}

\section{Conclusion}

Thus, the geodetic method is the most effective and economical in comparison with other methods for determining the motion of plates. But the most difficult and laborious in this method is the geometric leveling of the relief of hilly terrain. Therefore, trigonometric leveling performed with the help of electronic tacheometers is a reliable way to solve engineering, survey and geophysical studies of mountainous terrain and adjacent areas, where there may be faults and cracks in the upper layers of the lithosphere. The frequency of such measurements will make it possible to determine the rate of displacement of microplates or individual fragments over a six-month time interval, taking into account seasonal changes, since groundwater influences the stability of the coordinates of the benchmarks. The combination of GNSS, seismic, gravimetric and geodetic measurements will make it possible to develop a space-time system for monitoring deformation processes and build a three-dimensional model of the landfill. Such a system and model can be used not only in the Republic of Uzbekistan, but also for neighboring republics, where faults and cracks occur. In this case, all measurements should be brought to a single regional coordinate system and cartographic projection.

\section{References}

1. Y. Altiner, Analytical surface deformation theory for detection of the Earth's crust movements. Spring-Verlag. Berlin. Heilderberg. (1999).-102p.

2. G. Seeber, Satellite Geodesy. Berlin ·New York. (2003). -612p.

3. A.Rayzman, Issledovaniye Tashkentskogo zemletryaseniya 1966-1968 geodezicheskim metodom: Avtoreferat dissertatsii na soiskaniye uchenoy stepeni kandidata tekhnicheskikh nauk. Moskva (1970). - 11 p., rus.

4. Kh. Muborakov, E. Mirmakhmudov, A. Ruziev, B. Komilov, B.Toshonov, Using GNSS for education at national university of Uzbekistan. Science and Education in the modern world: Challenges of the XX1 century. Nur-Sultan, Kazakhstan, December (2019).Pp.43-47. 
5. Ch. Reighber, D. Angermann, G. Michel, J. Klotz, R. Galas\& the CATS-Team. GPS constraints on the distribution of deformation of the Tien Shan, N-Pamirs and behavior of the Tarim. 14th Himalaya-Karakorum-Tibet Workshop. Terra Nostra (1999).127.

6. R. Filjar, M. Filic, E. Mirmakhmudov, Categorisation of space weather and GNSS positioning quality indices for estimation of GNSS positioning performance degradation. Annual Baska GNSS Conference Proceedings. Croatia, Baska, Krk Island (2017).Pp.63-73.

7. B. Hofmann-Wellenhof, H. Lichtenegger and J. Collins, Global Positioning System. Theory and practice. Fifth, revised edition, Wienn, New-York: Springer (2001).-384 p.

8. Y. Bock, The use of the baseline measurements and geophysical models for the estimation of crustal deformations and terrestrial reference system. The Ohio State University Research Foundation Columbus, Ohio, 43212, (1982)

9. E. Blockmann, Combination of Solutions for geodetic and geodynamic application of the GPS.Ph.D. Thesis, Astronomical Institute, University of Bern Switzerland,(1979)

10. S. Molodensky, On the connection between gravity variations and vertical displacements of the Earth's surface. Academy of Sciences of the USSR, Institute of Physics of the Earth. Preprint, 4. Moscow, (1980). -17p. 